\title{
The strategic value of design for remanufacturing: a case study of professional imaging equipment
}

\author{
Nina Boorsma ${ }^{1}$ (D) David Peck ${ }^{2}$ (D) Tanya Bakker $^{3} \cdot$ Conny Bakker $^{1}$ (D) \\ Ruud Balkenende ${ }^{1}$
}

Received: 20 May 2021 / Accepted: 8 November 2021 /Published online: 12 February 2022

(c) The Author(s) 2022

\begin{abstract}
Remanufacturing offers an approach to extend product lifetime beyond its first use. After restoring products to original quality, they are reintroduced to the market. To make products more suited for this approach, and to increase resource-efficiency, design for remanufacturing can be incorporated for new product development. Academic literature points out opportunities for improved implementation particularly through early-stage design activities. This paper presents an in-depth, single case study into the opportunities and barriers to incorporate design for remanufacturing ine early-stage design. The selected case company is a producer of professional imaging equipment with an internal remanufacturing division. The company has decades of experience in remanufacturing and has introduced a company standard on design for End-of-Life. For data collection, employees from different departments were interviewed and observed. Design management theory was used to combine findings from all perspectives into a company-specific strategy map. This map shows departmental interrelations and dependencies, and exposes the opportunities for creating new value through design. At the case company, remanufacturing was found to be separate from, and secondary to, the development of newly manufactured products. If the strategy of a company is not attuned to developing products that serve multiple use-cycles, its execution will remain sub-optimal and remanufacturing will be a value-retention strategy in isolation. These findings may be valid for other companies that have remanufacturing operations, which are separate, as well.
\end{abstract}

Keywords Circular economy $\cdot$ Circular product design · Printers · Design strategy · Sustainable design $\cdot$ Soft barriers

\section{Introduction}

In seeking pathways to increased levels of sustainable production through remanufacturing, which is a value-retention strategy in the circular economy [1], design has a pivotal role to play [2,3]. Remanufacturing activity takes place within a factory,

Nina Boorsma

N.E.Boorsma@tudelft.nl

Extended author information available on the last page of the article 
where products are restored to original 'as-new' condition and performance, or even better, with full warranty, through following prespecified technical quality, engineering, and testing criteria [1]. The suitability for lifetime extension and the way products are designed prescribes the period they can be used effectively [4]. Literature has highlighted the benefits of designing products for remanufacturing as an opportunity to further increase resource productivity $[5,6]$. Yet, the implementation of, for example, design guidelines, often finds significant resistance in design teams, as optimising costs, time-to-market, and functionality for the first use-cycle are prioritized [7-10]. Understanding the benefits and value of strategic, early-stage, design for remanufacturing is key and can help improve the level of sustainable production [11-13]. The need for early-stage design integration is also acknowledged in the field of eco-design, which remanufacturing can be considered part of $[14,15]$. Adjustments to product design, however, only pay off if the products are returned to the original equipment manufacturer, or a partnered third-party, after use. The choice for a business model influences to what extent a company can regulate the number of products returning from the market. Bakker et al. [4] describe five archetypes of business models that are frequently used in circular settings. The archetypes that offer products-as-a-service tend to ensure highest return rates $[16,17]$.

To improve products' circularity in the context of remanufacturing, academic literature suggests aligning a product's design with the activities of the remanufacturing production process $[18,19]$. Much of the literature, [20] and case studies, adopt an operational perspective, for example: the development of engineering design guidelines, improvement of informational flows, or End-of-Life decision-making [21-23]. Design for remanufacturing is not, however, being widely applied in practice [24, 17]. There is a lack of cases that provide sufficient insights to facilitate addressing the strategic aspects, including how to develop the organizational environment so that it supports and drives remanufacturing towards more successful outcomes [25]. This research aims to look beyond the scope of detailed, operational design engineering and moves into the field of early-stage, strategic design, in order to help answer the following research question:

How can design management support the strategic integration of design for remanufacturing in industry?

This question has been addressed through the analysis of a single case study. The aim of this study is to explore how remanufacturing is integrated in the earlier design stages in a real-world context and what lessons can be learned from this case that are relevant for other industries. The selected case company is an original equipment manufacturer of professional imaging equipment. The company has remanufactured products for over three decades. To analyse the case, a design management perspective is taken. The use of a design management framework helps in recognising the opportunities and barriers to the strategic integration of design for remanufacturing.

In the second section, the background section, this paper provides a theoretical background on early-stage design activities and the role of design management. In the third section the methodology is presented. The fourth and fifth sections introduce the case study company and show the case analysis. The final sections discuss the main findings and the conclusions. 


\section{Background}

Even though there is a lack of dedicated cases, the function of early-stage design has been recognized in literature. This can be seen from the acknowledgement that the earlystage design phase, which includes strategic and conceptual design, can be valuable to the integration of remanufacturing $[26,18]$.

There are a number of studies describing the functions of early-stage design for remanufacturing. Concerning product conceptualization, Gehin et al. [26] observed that companies should identify potential future markets for remanufactured products during the early phase of the original design process. Singhal et al. [3] recognized an opportunity for design strategies like upgrading, which require early-stage conceptualisation, to generate profit for the company. Subramoniam et al. [27] particularly bring up integration in early-stage design to prevent decisions that go against building a good remanufacturing business case. The authors promote cross-departmental collaboration to help identify possible design barriers or trade-offs. In their paper, Lindkvist-Haziri \& Sundin [22] explore strategic ways to allow design engineers to learn from insights gained at the remanufacturing department, and with that seek to increase commitment to improve designs. The study identified four steps that will help transfer design information from the remanufacturing to the design department. First, the current situation is assessed, then an outline for a future vision is created, feedback actions are implemented, and finally an evaluation takes place. Early-stage design was also highlighted by Krikke et al. [28] with regards to the need for identification of high-value parts with a stable technology, since these are critical in making the business case for remanufacturing viable. Strategic design elements related to marketing and business development were marked as critical by Copani \& Benham [12] in allowing for future-proof remanufacturing concepts.

Several studies highlight the barriers to early-stage design integration. Hatcher et al. [5] found that companies are primarily focused on cost savings, optimizing designs for a single/ first use-cycle, and have difficulties predicting customer demand for successive use-cycles. Another major barrier from the same study was the lack of designers' motivation, which is linked to the absence of remanufacturing objectives in design briefs. In case it is adopted, Hatcher et al. [5] argue that commitment towards applying remanufacturing design guidelines decreases when time pressure to develop products increases. With regards to market potential, D'adamo \& Rosa [29] identified having the expertise to effectively position remanufactured products on the market as an industry knowledge gap. The importance, and value, of early-stage design is widely acknowledged, yet its application in industry, and an understanding of what barriers and opportunities companies may encounter, has not been researched in detail.

Design management is a cross-disciplinary research field that tries to bring together design-based and management-based knowledge and practices. Situating this study at the intersection of design and management is deemed useful, because it allows us to ask questions such as "What do specific design solutions demand from management in terms of strategic attention, managerial priority, organizational change, investment or relationship management?' [30]. Moreover, design management is a field of study that is concerned with developing and integrating design, and bringing awareness to its strategic potential $[31,32]$. In a previous paper, an initial set of design management roles for remanufacturing was defined based on literature and interviews with companies [11]. Key roles were 'connecting different disciplines within the company to develop 
relevant, high-quality offers', 'making technology roadmaps at an early design stage', and 'identifying the intangible value of remanufacturing to a company'.

This paper builds upon Borja de Mozota's [33] balanced scorecard for design management. A balanced scorecard is a tool that measures how well an organisation's intangible assets support the outlined strategy and pinpoints opportunities for improved effectiveness [34]. It is a management system that relaxes the primary focus on financial objectives and shifts it to one divided over four perspectives: the customer, process, learning, and financial perspective. These four perspectives are used to analyse the case study of this paper. Borja de Mozota assigned values of design to each of these perspectives within the scope of design management.

Before describing these values in the context of remanufacturing, an adaptation to one of the perspectives wasill be made. The term 'financial perspective' was found to be too narrow for the type of value this perspective covers in the context of sustainable production. The term 'value perspective' is considered more suitable. In addition, a new value descriptor was added to this perspective to acknowledge the importance of creating environmental and societal value in addition to making profit, which is the descriptor 'Improve triple bottom line'.

The functions of the perspectives will now be described in more detail, in particular, describing the way they relate to remanufacturing (Fig. 1). The customer value perspective evaluates the way to create value to the market through remanufacturing. It addresses the company's current approach in finding opportunities to remanufacture products and

\section{Customer perspective}

Market share for product portfolios that include remanufactured products Brand image of remarketed products Customer satisfaction through products that serve multiple use-cycles

\section{Learning perspective}

Recruit high potential profiles with circular knowledge and skill

Competent staff

Motivated and empowered staff

\section{Process}

\section{perspective}

Improving the circular product

innovation process

Improving the remanufacturing production process

Design in information management for closed-loop production systems

\section{Value} perspective

Increase turnover for remanufactured products

Improving intangibles

Improve ROI

Improve triple bottom line

Fig. 1 Balanced scorecard for design management applied to remanufacturing, adapted from Borja de Mozota [33] 
increase market share. It also addresses how assets are used to satisfy market needs. The process perspective covers the activities that take place in the design and production processes. It focuses on innovative product improvements that take remanufacturing into consideration, it optimises products for the remanufacturing process, and manages the required product information. The learning perspective is the key perspective in finding novel ways of operating. This perspective is about developing new skills and expertise to make the most value out of remanufacturing. It focuses on renewing (design) visions, explores new ways for design to add value, and cultivates the mind-sets needed to take remanufacturing a step forward. The value perspective connects remanufacturing design with business metrics. This perspective is focused on expressing how designing for remanufacturing contributes to increased turnover, intangible value, and improved return on investments, as well as improvements in the triple bottom line.

\section{Methodology}

This section presents the methodology applied for the study, including the selection of the case, data collection, and data analysis.

\section{Case study research}

This paper took an exploratory approach in finding the opportunities and barriers to the strategic integration of design for remanufacturing in industry. A single case study research was selected to understand what remanufacturing means to its wider strategic context, related to product design, and in what ways additional value can be created [35]. Moreover, case study research offers diverse and rich data from multiple sources, with the possibility to follow up on topics that are brought up during the inquiry.

The selected case company is a producer of professional imaging equipment that operates in a business-to-business industry. It is a frontrunner in the field of remanufacturing, which has been applied for over three decades. The company has a large in-house design department and follows a design-driven approach to produce complex and durable products. The company's experience, as well as attempts to mature their remanufacturing approach, formed a rich basis for a case study. The company has the required level of awareness, ambition, and knowledge concerning the topic.

\section{Data collection}

The case data was collected inover four weeks by conducting on-site interviews and by making observations (Fig. 2). Four departments were included for this study: the business development, product development, remanufacturing, and compliance departments. A total of 35 interviews were conducted in a semi-structured face-to-face setting, and lasted between 40 and 80 min (Table 1). Additional open, short interviews were carried out with the remanufacturing technicians.

The interviewees were selected based on their role within the departments and their specific experience with the product life-cycle (including End-of-Life). The following topics were discussed during the interviews: processes in place to support Design for Remanufacturing; technical and strategic barriers and opportunities; good practice examples of 


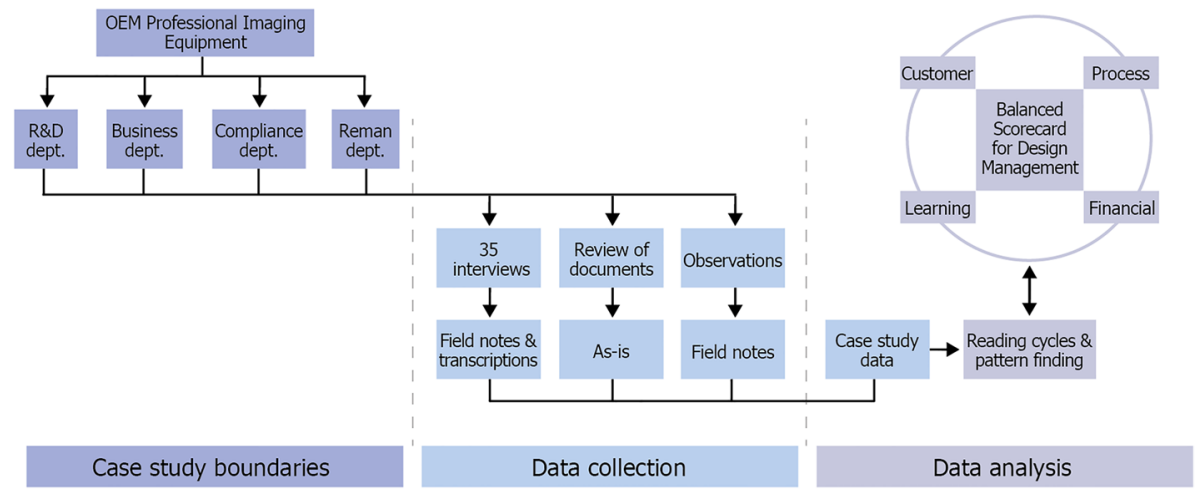

Fig. 2 Methodology flow chart

successful remanufacturing, and; examples where remanufacturing could not or would not be applied, see the Appendix.

The interview data from the first week was collected through making field notes. The interviews in the second, third, and fourth week were recorded and transcribed. In several instances, follow-up interviews were planned to let the interviewees respond to topics brought up by other departments, ensuring internal validity [35].

Central to the study is the professional imaging equipment that the company produces. Data about these products were collected through company documentation, observations, photos/ images, and interviews; including multiple sources of evidence enabled data triangulation [35]. Additional data were collected through participant and non-participant observations and by reviewing company documents. The observations concerned the operations at the remanufacturing workshop with its different stations, from inbound to disassembly to cleaning, the quality and types of systems remanufactured, as well as the detailed operations (such as the way remanufacturing technicians would consult the information system to get access to specific instructions). These observations were documented in a field diary, structured following date and type of event, and by taking photographs. The events were described in short notes about the activities of employees, the process setups, atmosphere, insights and ideas from the note taker, possible follow-up questions, and remarks by employees.

\section{Data analysis}

The balanced scorecard, introduced in the background section, was used for the case analysis, by providing four main themes. The method for thematic analysis proposed by Castleberry \& Nolen [36] was used to analyse qualitative data in detail.

As a first step, the compiled data was coded to group similar data using an open coding scheme. After this step, codes that revealed patterns or relations were linked to one of the themes. To move towards interpretation, a narrative was created for each theme based on the causal sequences found during the reading-cycles. This narrative was further detailed and improved upon by iterating and revising early tentative statements. Creating such a narrative was a helpful way to convey all the details, interdependencies, and relations of the events observed at the case company, see the example in Table 2 . This process was repeated 


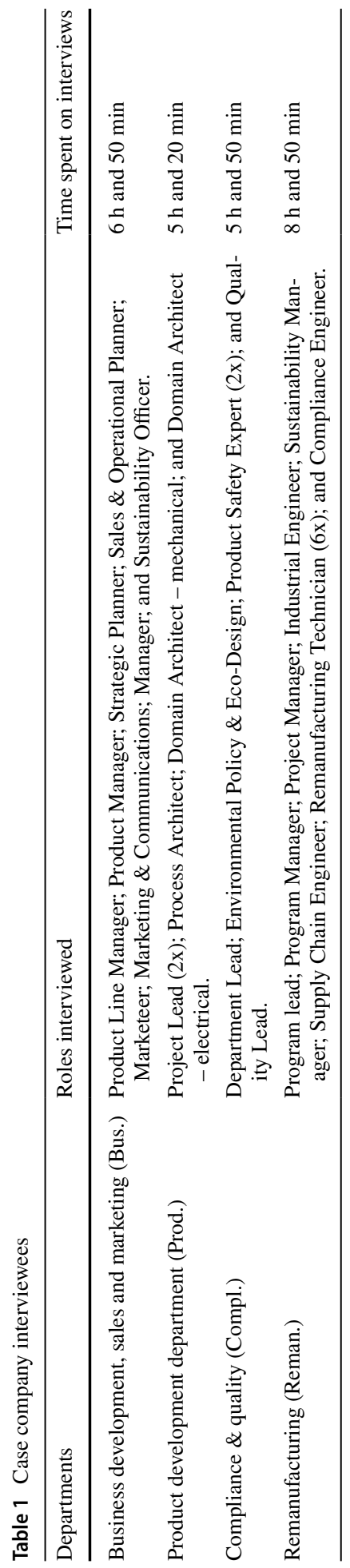


Table 2 An example of how the case narrative was developed based on the interview transcripts

\begin{tabular}{ll}
\hline Sentences from transcript & Case narrative \\
\hline $\begin{array}{l}\text { The market maturity curve largely determines the } \\
\text { possibilities for remanufacturing }\end{array}$ & $\begin{array}{c}\text { At the case company, remanufacturing is seen as a } \\
\text { very effective strategy to fill gaps in the product } \\
\text { portfolio for newly manufactured products. It }\end{array}$ \\
$\begin{array}{l}\text { Remanufacturing is a low-effort option to provide } \\
\text { products to customers as we do not need a new }\end{array}$ & $\begin{array}{l}\text { is used when products, that are already on the } \\
\text { market, are taken out of production, while there } \\
\text { development cycle to do this. }\end{array}$ \\
$\begin{array}{ll}\text { - We plan to replace one technology by a new version } \\
\text { for this category. Remanufacturing is used to cover } \\
\text { the remaining customer demand. }\end{array}$ & \begin{tabular}{l} 
appears to be market demand. \\
\hline
\end{tabular}
\end{tabular}

several times with all co-authors, as well as a company-contact. As a last step, conclusions were drawn from the narratives to formulate an answer to the research question.

The results were reviewed by key informants from the case company to corroborate the findings. This took place in two stages. In the first stage, after an initial round of data analysis, a short report with key findings was shared and reviewed by the company; in the second stage, after structured analysis, a more elaborate and detailed set of findings was shared and reviewed in several rounds.

\section{Case description}

The case company is a globally operating original equipment manufacturer in the imaging equipment industry with a long history of remanufacturing. The remanufacturing production facility is located in Europe, next to the development and manufacturing plant for new products. The brand is known for its high standards with regards to product safety, quality and environmental impact, which helped in initiating its first remanufacturing production line in the 80 ' s. The case company is strongly technology-driven, its product development department employs over 500 people.

The case company was highly successful in combining manufacturing and remanufacturing back in the 80 ' s. To give an example, for one of the products the company produced 120 new printers, and 100 remanufactured printers, each day. The remanufacturing department employed about 200 people spread over different locations. At that point, the product portfolio was relatively uniform. With an increase in variety in the product portfolio over the years, the opportunities for product and part remanufacturing diminished. Remanufacturing activities did continue, yet on a smaller scale. This increase was caused by a strong focus on the rapid development of new printing technologies to increase speed and improved user workflows. The remanufacturing process got decentralised and shifted to the regional divisions of the company, weakening the link with new product development.

In 2018, the company took a step towards renewed integration of remanufacturing by again centralising, refocusing, and renaming the remanufacturing department, as well as developing a company standard for ease-of-disassembly. The remanufacturing production capacity did scale up after renewing the operations. The product portfolio of newly developed products of this division contains about thirty products. Two of these products are remanufactured in full, two to three each month. And an additional 1200 spare parts are remanufactured each month. At the moment, around thirty people are employed at the remanufacturing department. 


\section{Results}

The results section follows the four design management perspectives that were introduced in the background section: the customer, process, learning, and value perspective. For these perspectives, the ongoing processes related to design management to support remanufacturing are described, as well as their associated barriers and opportunities. To put the case into context, four product types are introduced and referred to throughout the results section. The descriptions of the products can be found in Table 3.

\section{Customer perspective}

All of the activities at the case company are essentially designed to create value for their customers. In what way remanufacturing is used to create this value is discussed in this section. Firstly, by explaining the current market opportunities the company sees, as well as discussing the frictions present in early-stage design.

\section{Remanufacturing as an afterthought}

At the case company, remanufacturing is seen as a very effective strategy to fill gaps in the product portfolio for newly manufactured products. It is used when products, that are already on the market, are taken out of production, while there appears to still be market demand. In such a situation the company appeals to the potential of products to be remanufactured and reintroduced to the market. The following examples of products A and B illustrate the value thisit generates rto customers.

In the case of Product A, the company expected the market to have switched to full colour printing. However, market demand for black-white printing remained unexpectedly high. To meet this unanticipated market demand, a remanufacturing production line was initiated. This way, customers would still have access to a product for black-white printing.

In the other example, the company did not have a fitting successor for Product B at the time it was taken out of production. To provide the market with a similar offer, a remanufacturing line was set up. A significant enabler was the product's hard-to-mimic technology of this specific product, which kept competitors and brokers out of entering the market. This way, the customers' need for the wide-format colour printers was met.

These examples show that the company sees remanufacturing as an option only if market demand is proven to remain high after the product is out of manufacturing production. The risk of competing with new products was given as the main reason not to consider remanufacturing earlier on in the design process; this was based on the premise within the company that the target groups for remanufactured products and their newly designed successor have significant overlap. To illustrate this, at the moment Product D, the successor of Product A, will enter the market, the remanufacturing line of Product A will be halted. The two products are considered too similar to be produced simultaneously, causing the threat of market cannibalisation, which is perceived as a risk, especially for this expensive product type.

\section{Early-stage design integration considered impossible}

A closer look into the dynamics of early-stage design may help in understanding the exact opportunities and barriers for the company experiences to use remanufacturing to meet 


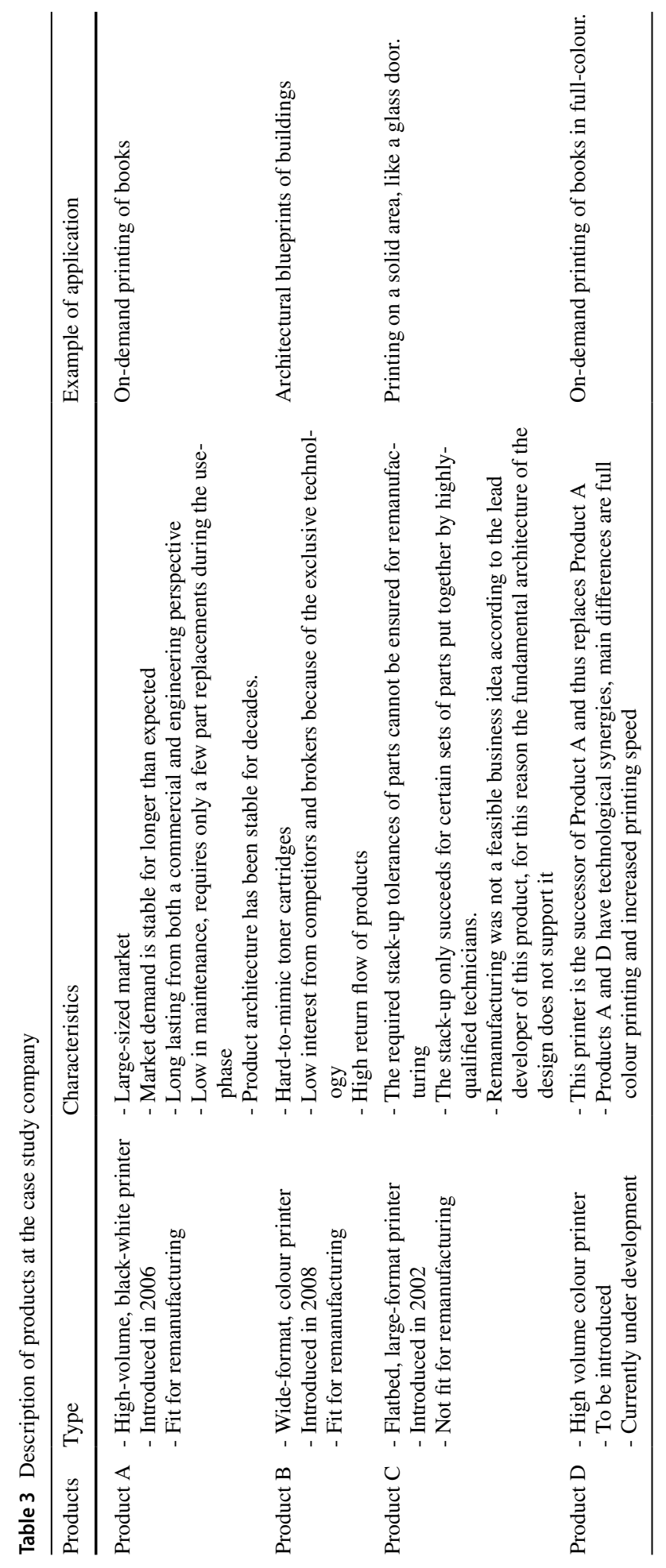


customer demand. Where initially there does not seem to be much room forthis early-stage design integration, some opportunities did arise.

The Product Line Manager (Bus.), who oversees and manages the development process from start to finish, considers using remanufacturing as a tool to meet customer demand in early-stage design as nearly impossible. This is due to the risks associated with predicting future market demand, where estimations for market dynamics, technological development, and competitor behaviour all need to be considered at once. Besides, interviewees from both the business development and product development mention that the customer's mind-sets are typically programmed for new features, improved performance, and aesthetics. Such new features are improved levels of user workflow integration, improved customer experience, and increased productivity.

Closely related to the perspective on market demand is the market segmenting approach applied at the case company. This has to do with how the company divides the market into different customer segments. Currently, the dominant parameter in the segmentation approach is based on printing speed against costs. While this may indeed be important to customers buying the latest technology, it may not represent customers interested in remanufactured products well. According to the Product Manager (Bus.), a very limited amount of research is done to collect insights from the market for remanufacturing, which complicates defining market segments for such products. This also means that the level of differentiation between these customer segments has not been substantiated through customer research.

A reflection from the sales forces with regards to remanufactured products, is that they are used to offering customers new features instead of existing technology. Remanufactured products are therefore considered a difficult sell. Besides, the company incentives the sales of newly manufactured products significantly more than selling remanufactured products. This means that customers are not likely to hear about remanufactured product offers in the first place.

An opportunity for using remanufactured products to meet market needs was pointed out by the Strategic Planner (Bus.). He proposes a strategy where newly manufactured products, containing the latest printing technologies, are used to target new markets, whereas remanufactured products can be offered to the more mature markets. According to him, combining remanufactured and newly manufactured products would allow the company to focus their innovation capacity and still serve the needs of all customer segments. This way, careful management of the product portfolio could allow Products A and D to be sold simultaneously. In such combined portfolios, the stability of the product technology becomes the main driving force for remanufacturing.

\section{Fragmented efforts deliver suboptimal results}

To make remanufacturing attractive to the market, input from all departments is required. An example would be the need for marketeers to inform the market about possible remanufactured product offers. To inform the market in time, the sales organisation needs to be well-informed about the available offers. Their commitment is crucial for the commercial success of remanufacturing. The Program Lead (Reman.) notices that most departments are mainly concerned with developing and selling new printing technologies. According to him, making a greater financial impact through remanufacturing would be an effective way to get other departments committed.

To summarise, the case company uses remanufacturing to bridge gaps caused by unforeseen market demand, which cannot be met with newly manufactured products. Although 
remanufacturing is used to meet customer demand, early-stage design activities, like customer research and product portfolio management, do not consider remanufacturing. Commitment from other departments, and their orientation towards remanufacturing, would be important to successfully serve the market. In addition, having greater financial impact would draw out increased levels of commitment.

\section{Process perspective}

Understanding how early-stage design decisions influence operationalising design for remanufacturing is the next step. This section dives into the processes in place and earlystage activities that ensure design integration. Besides covering the company standards for design, this section looks into product performance and required design competencies. It will also shed light on what part categories require early-stage involvement to support remanufacturing. This is essential for maintaining high product quality over the long term.

\section{Operationalising design for remanufacturing through company standards}

Under guidance of the compliance department, about 50 company standards help in designing compliant (to legislation), high-quality, and safe-to-use products. One of these standards is concerned with the End-of-Life of products. The first version of this standard was purely about being compliant to the European Union's Waste Electronics and Electrical Equipment (EU WEEE) directive, the EU Battery directive, and the compulsory markings that need to be applied to plastic parts.

To make designs better suited to End-of-Life scenarios, like remanufacturing, a new section on ease of dis- and reassembly was added to this company standard in 2018. About 30 design guidelines were added to its Appendix. These 30 guidelines were developed in a multi-disciplinary team that involved the remanufacturing department, the compliance department, the business development department, and was led by the product development department. The team aimed at reducing the environmental impact of, and reducing labour- and material costs during, remanufacturing. It was also aimed at improving the alignment between stakeholders across the remanufacturing value chain. Examples of the guidelines are the following: to minimize variation of material types, to apply easy-to-see handles, to design light-weight units $(<12 \mathrm{~kg})$, to use standard screws, and to avoid the need to turn units during disassembly.

A certain level of flexibility is required for the guidelines, since their implications differ from product to product. Therefore, the guidelines are formulated qualitatively. This can be illustrated for the case of Product C. Enforcing these guidelines would require changes in the product architecture. Such impactful changes would drive up the design budget significantly. The Process Architect (Prod.) working on the design of Printer D is optimistic about the design guidelines, as he states: "From my point of view, these [guidelines] are relatively easy to integrate into the design process."

A downside of not having quantitative guidelines is that the level of implementation is hard to assess; yet, the design engineers fully rely upon these company standards. Without any tools for measurement, however, the effectivity of the company standard cannot be monitored. New versions of the standard proposing quantified design guidelines for remanufacturing have found significant resistance from the product development department.

Personal perspectives of lead engineers, and their affinity to remanufacturability, also affect the level of implementation. One of the Domain Architects states the following: "I 
have less affinity with this subject, so it wouldn't be my focus. Even if this has been written down in a [company standard]. Everything becomes fluid when under pressure." $\mathrm{He}$ continues by saying that the implementation of new requirements should take place before the end of the conceptual phase; after this point the product functionality and budgets are frozen, which means that it is costly or technically impossible to make big changes.

\section{Remanufacturing process performance is hard to capture through key performance indicators}

When it comes to operationalising through measurements, the Program Manager (Reman.) shares that there are no key performance indicators (KPIs) that impact remanufacturing directly. This means that the existing KPIs of the company do not support or counteract remanufacturing. He expresses no concerns about the absence of these KPIs and explains that the department does have targets for the product return rate, which is the fraction of products returning from the market, and the delivery performance. The return rate for some products turns out to be relatively low, about $30 \%$. The department is currently looking for ways to increase this number.

Drafting new KPIs is a challenge, according to the Program Manager. It is easy to cause unwanted side-effects, "One of the unwanted side-effects is poor quality. KPIs do not easily help steer this process in the right direction. In some way they can always be avoided or fulfilled with the least possible effort."

\section{Managing the quality and safety of products that serve multiple use-cycles}

In producing products, high quality and safety are core values to the case company. All processes are optimised to ensure these values throughout a product's first use-cycle. In what ways these high-quality and safety levels are maintained during remanufacturing will be explained based on the interviews with the development, compliance, and remanufacturing departments. Out of these interviews, several categories of parts were identified that primarily determine the quality and safety levels beyond the initial use-cycles. These are the identified part categories: (1) high-value parts; (2) software-related parts; (3) safetycritical parts; (4) procured parts; and (5) spare parts.

\section{High-value parts}

Professional imaging equipment often contain several high-value parts that make the reverse logistics and remanufacturing process viable from a cost perspective. For instance, for Product B, these are the printheads containing the print nozzles. This printer contains a number of print heads which make up the largest share of the printer's value. For this product, a combination of parts harvesting (e.g. taking back printheads) and full product remanufacturing makes the process viable.

Identifying high-value parts at an early design stage can help to identify opportunities for remanufacturing early on. One of the Domain Architects (Prod.) explained: "I don't think making an estimation about the remanufacturability of the different parts is time-consuming. Besides, any estimation is better than the non-estimation we are making now. I would estimate an average remanufacturing potential of about $80 \%$ of the parts. Important to keep in mind is, that the most valuable parts should be included in this $80 \%$ for the process to be viable." 


\section{Software-related parts}

Another essential category includes the software-related parts. Keeping operating systems up to date and secure is of increasing importance to companies working with products connected to networks and the internet. Since imaging equipment connects to such networks, their operating systems need to be secure too. Product B, for instance, may be used by companies to print blueprints for the building industry. This may contain sensitive information which should not be accessible through hacks and other data leaks.

The operating systems of the printers are currently optimized to serve a single usecycle, according to one of the Project Leads (Reman.). This means that the operating systems may not allow for software updates after this first use-cycle of about 7 years. If this is the case, the printer is not suited for remanufacturing. An interviewee from the product development department stated that "upgradable software-support-life is not a go/ no-go criterion for the product definition." Introducing such a standard would let more products be suitable for remanufacturing.

\section{Safety-critical parts}

To provide as-new product quality, the information about the safety-critical parts needs to be managed carefully. The remanufacturing department is confident about their level of information management concerning these aspects. According to the Program Manager (Reman.) and remanufacturing technicians, qualification tests are the same ones as used for newly manufactured products.

The Product Safety Expert (Compl.) expresses his concerns regarding the evidence collected about lifetime expectations of safety-critical parts. He estimates that about $10 \%$ of a printer's parts are safety-critical, most of which are the ones containing electronics. He is, for example, uncertain about the duration of the effectiveness of fire retardants in printer covers. According to the him, lifetime tests are needed to get a proper understanding of the behaviour of these parts. The remanufacturing department only reuses the safety-critical parts when they pass the original qualification tests.

\section{4. $\quad$ Procured parts}

Another, less critical, yet important category of parts was again pointed out by the Product Safety Expert (Compl.), which contains the procured parts. According to him, managing and tracing certificates of these parts is important to guarantee as-new quality. This information about externally sourced sub-assemblies, however, is often harder and costlier to acquire than for in-house parts. The Program Lead (Reman.) is in charge of monitoring certificates of these parts.

Procured parts can also become scarce when suppliers for any reason shut down production. In those cases, a 'last time buy' is often still an option. This, however, does generally not include the scenario to remanufacture.

\section{Spare parts}

The final category of parts is spare parts. Spare parts are essential for remanufacturing and for fulfilling service agreements. During the development of new product platforms, an estimation of the number of required spare parts is made. This is done based on expected 
production levels and the duration of the service agreements. Since the company does not plan for remanufacturing from an early stage on, the calculations for spare parts do not include a scenario for remanufacturing. When the company decides to remanufacture a product, it relies either on an extension of the production of newly manufactured spare parts, or on parts harvested from the market. In the case of product $\mathrm{B}$, the need for spare parts was fulfilled by setting up a remanufacturing line for the print nozzles.

To summarise, this section describes the processes to manage product quality beyond the initial use-cycle. By introducing new design guidelines in 2018, the company tried to improve the ease-of-disassembly of products. The development and implementation of (additional) quantified or hard requirements remains a challenge, as not all stakeholders support this. Apart from several KPIs regarding the acquisition of products from the market, indicators are not used to regulate processes supportive of remanufacturing. The case company has a clear idea of the part categories critical to remanufacturing, however, the design and production (quantity) for these parts do generally not consider a remanufacturing scenario.

\section{Learning perspective}

This section dives into current mind-sets towards remanufacturing, the skills and training needed to transition towards circular thinking, and the ways to create awareness and acceptance of remanufacturing. Organisational change towards circular production systems at the case company is largely driven by bottom-up initiatives.

\section{Competences for high-quality remanufacturing through experience-based learning}

The skills needed to remanufacture products are developed through experience, there is no external educational track to train remanufacturing technicians. To reach the objective of delivering high-quality products, the remanufacturing technicians require extensive experience and expertise. Such experience is built up over the years while working at the production line of newly manufactured products. The technicians need to be familiar with the information system that is used: to know where product information is exactly located, but also to know how the products are constructed. Rebuilding a high-volume black-white printer (Product A), is more likely to succeed with having the experience of putting it together at an assembly line. These skills, therefore, are difficult and time consuming to transfer to new employees. Skilled technicians are therefore recruited from within the company, based on specific expertise profiles. The same is true for non-engineering skills for remanufacturing. The experience and knowledge from working with newly manufactured products form the basis for remanufacturing competencies.

\section{Linear thinking remains the norm}

Previous sections already touched upon customers' critical mind-set towards remanufacturing. The design engineers' mind-sets are just as critical. Most interviewees from the product development department recognize that there is a lack of awareness and interest in remanufacturing amongst engineers, including themselves. The Process Architect (Prod.) and Domain Architects (Prod.) argue that this one of the main reasons that remanufacturing is not included in the assignment they receive from the business development department. And if the business development department does not prioritise remanufacturing, it does not end up into the design brief, like was the 
case for Product C. The Process Architect (Prod.) notes that actions taken towards the integration of remanufacturing either comes from the remanufacturing or compliance department, or from individual initiatives driven by intrinsic motivation. The lack of integration and prioritisation is also reflected in the fact, that the central remanufacturing department was shut down for a number of years in the previous decade. The ease of halting the operations is a sign that this department's strategy and mission are relatively independent and detached from the development of new products.

\section{Branding as a tool towards acceptance}

Internal and external acceptance of remanufacturing are difficult to cultivate. The Program Lead (Reman.) is well aware of the attitude towards remanufacturing within the company, i.e. the level of internal acceptance, and within the market, i.e. the level of external acceptance. A common barrier is uncertainty about the quality potential and/or quality offered through remanufactured products. The Program Lead (Reman.) explains that this perception can be influenced by building a separate brand image for remanufactured products. According to the Program Lead (Reman.), trust is generated through building an image of the quality and performance of the products, as well as providing sufficient information. Renaming and repositioning the remanufacturing department several years back, was a first step in the department's branding strategy. The activity of creating this brand currently lies with the Program Lead (Reman.) himself and his direct colleagues.

To summarise, adjusting mind-sets and having clear drivers are needed to integrate design for remanufacturing in ways that not only underpin the engineering value, but also the strategic value. Lead engineers have indicated a need for a strategic direction, which should be provided by the business development department. This would allow remanufacturing to be adopted in the design brief. When it comes to the development of skills and expertise, informal educational pathways are the norm. Lastly, to move towards increased levels of commitment and trust from all departments, the first step is to use branding as a tool.

\section{Value perspective}

This section discusses the tangible and intangible value of remanufacturing, and what collective efforts are needed to optimise the business cases. In more detail, this section covers the process of setting up business cases for remanufacturing and it shows how the remanufacturing department seems to be a rather separate entity within the company.

\section{Business case calculations may not reflect the actual potential}

The impact the remanufacturing department makes within the company is indirectly related to the investments the company is willing to make in Design for Remanufacturing. Having high product volumes and high numbers of product types that are remanufactured, increases the company's willingness to invest in adjusting designs. From a value perspective, there are several factors that influence the developmnet of business cases for remanufacturing.

The initial business case of new products does not include a remanufacturing scenario. The reason for this, is that remanufacturing does not create any revenues in the first years after the new product is launched. The calculations for remanufacturing business cases are therefore made separately. 
The Program Manager (Reman.) expresses that there is room for optimization when it comes to developing these business cases. The most significant costs for the business case include transportation costs, production costs, and the costs of return credits. The Program Manager (Reman.) argues that it would be beneficial to exclude the return credits from these calculations, since this is a transaction made within the company itself. The revenues, on the other hand, are made up from the sales of the remanufactured product. The Program Manager (Reman.) argues here, that usephase revenues, i.e. revenues from the sales of toner and from the service agreement during a printer's use-cycle, should also be included for the revenue calculations, since they are enabled through remanufacturing. The reason why they are excluded at the moment, is because the remanufacturing department is seen as a production department that produces durables and does not produce consumables (i.e. toner) or offer services. The reason why the Program Manager is concerned about the details of the business cases is, that the department does not receive a production budget, and is fully dependent on the success of business cases.

The level of product return rates also influences the success of a business case. This can be significantly improved through timely communicating the needs for certain types of products to the sales organisation. In the case of Product B, this was done effectively, causing the return rates to be higher than usual.

The Program Manager (Reman.) continues by saying that the business case for remanufacturing spare parts (e.g. parts that are used inside the company in servicing and remanufacturing operations) is made at an earlier stage than that of full printers. The enabler here, is that spare parts are already needed from the start of the first use-cycle in servicing and can directly contribute to lowering operational costs. Another enabler here, is that end users do not interact with these servicing parts directly since they are positioned behind the printer covers. Acceptance of using remanufactured spare parts, therefore, does not play a significant role. Having a spare part remanufacturing line in place, however, may also support the business case for full remanufacturing, like in the earlier mentioned example of the print nozzles for Product B.

The constraint the department has when it comes to scaling up the production of remanufactured spare parts, is that they are not allowed to charge market-conform prices for the internal pricing. This is decided by the business development department. In other words, even though the department is the single supplier of these parts, after they are taken out of manufacturing production, the pricing of spare parts remains unchanged. As a result, the remanufacturing department does not have the advantage of being the single supplier.

To summarise, this section describes how the value of (design for) remanufacturing is influenced by the development of business cases. The business case calculations for remanufactured products are secondary to newly manufactured products and leave room for improvement in terms of effectiveness. They are primarily focused on tangible value, i.e. euros. Therefore, the additional strategic value brought in by design is not separately assessed or considered.

\section{Discussion}

The data analysis of the previous section was based on Borja de Mozota's [33] balanced scorecard for design management. The results discuss remanufacturing from each of the four perspectives of this balanced scorecard. This section discusses and visualises the links 
and interrelations between the four perspectives by means of a strategy map. A strategy map is a framework that puts together the main results of the four company perspectives into one visual [34]. The focus of this framework is to examine the value creation by linking the intangible assets of the perspectives. This map helps in clarifying the contributions of this study.

Several adaptations were made to the lay-out of the strategy map prior to use. The reason for these adaptations was to ensure an optimal fit within a context of improved sustainable production. The process, customer, and value perspectives were rotated to all be connected to the learning perspective, to acknowledge the fact that this perspective supports the activities in the other perspectives (Fig. 3). The resulting strategy map, which is presented in the form of an advice, can be seen in (Fig. 4). All perspectives are equally important and the elements included in this map are not prioritized according to the order of implementation. They form a mix of shorter- and longer-term solutions. The map shows how design management theory can be used to identify elements that can feed into a design strategy that is attuned to developing products that serve multiple use-cycles.

Currently, the case company's remanufacturing design guidelines do not get prioritised during new product development. Where other recent case studies on the topic focus on operational aspects, such as optimising the transfer of process knowledge to optimise product design and process planning [22, 21], the strategy map presented in this paper suggests a strategic approach towards increased effectiveness of design. A first important link that this map shows is that of the strategic value of remanufacturing to the product requirements. This value stretches beyond seeing remanufacturing merely being a last resort to fill a gap in the product portfolio; its strategic value is acknowledged. Ansari et al. [37] list many possible advantages, i.e. creating market opportunities, saving resources, improving the brand image, increasing competitiveness, and increasing productivity. Similarly, advantages were found in studies by Kerr \& Ryan [38], with regards to reduced environmental impact of photocopiers, and Östlin, with regards to applying new business strategies to ensure product returns from the

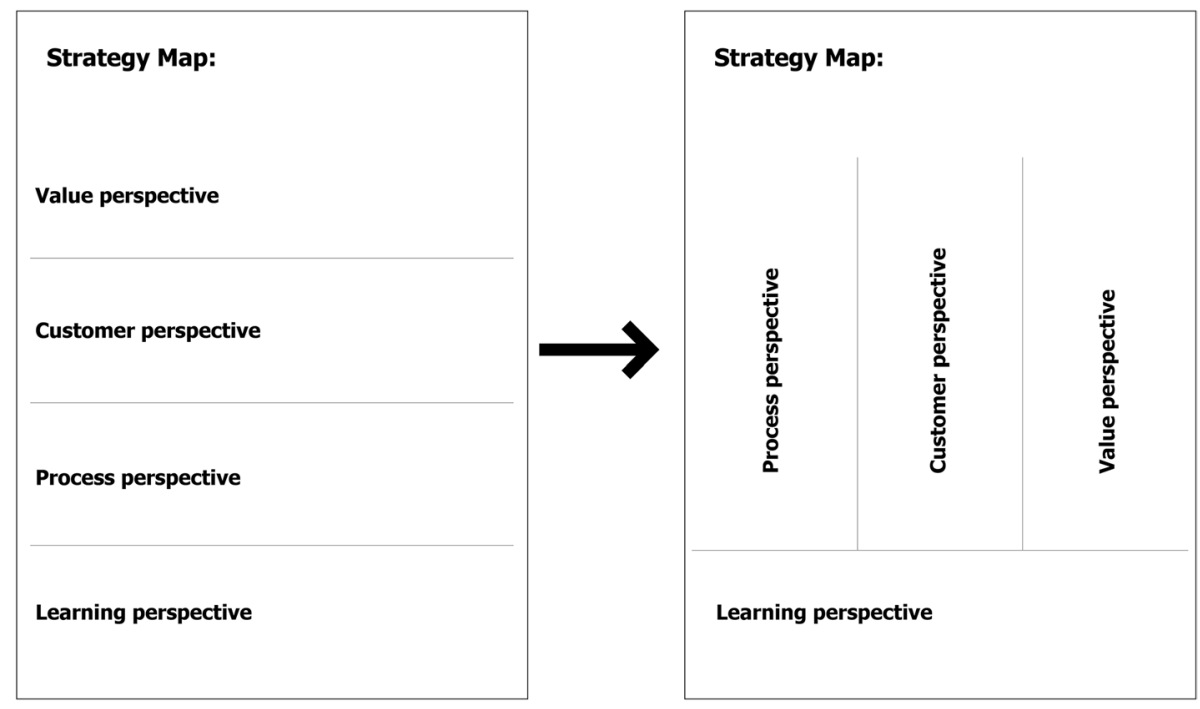

Fig. 3 Adaptation to the strategy map lay-out 


\section{Strategy Map: \\ Design Management for Remanufacturing}

A case study of Professional Imaging Equipment

\section{Process perspective}

Customer perspective

Improving innovation process

Improving production process

Design in information systems management

\section{Market share}

Brand image

Customer satisfaction

\section{Value \\ perspective}

Increasing turnover

Improving intangibles

Improving ROI

Improving triple bottom line

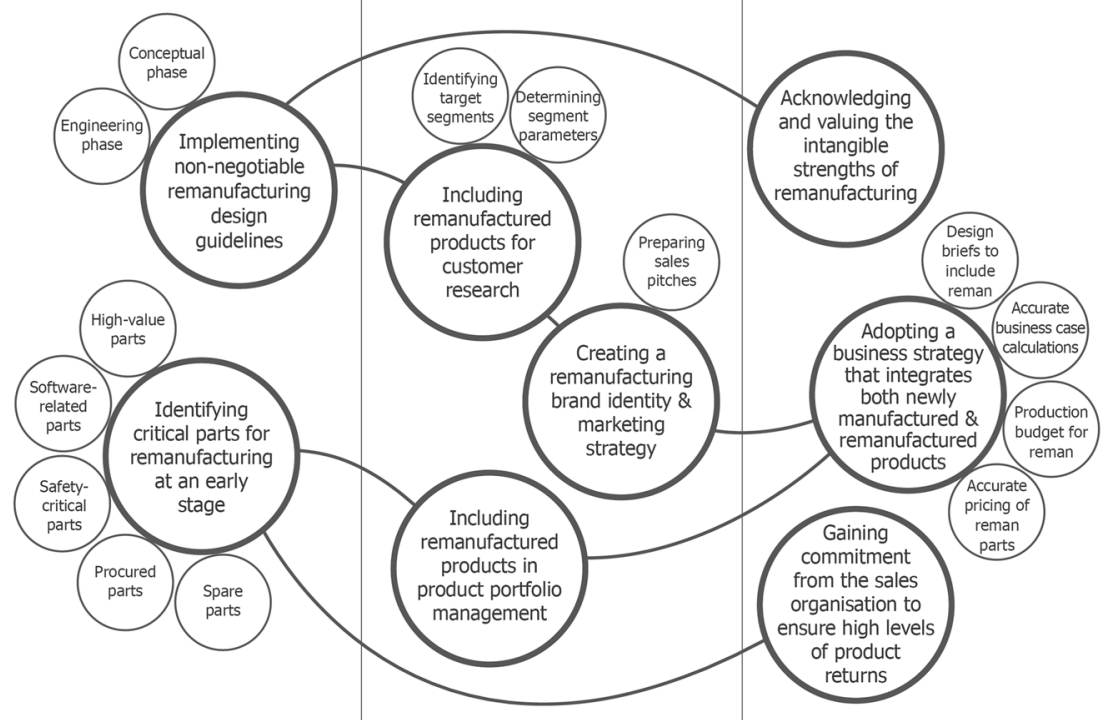

\section{Learning} perspective

Recruiting high potential profiles

Competent staff

Motivated and

empowered staff
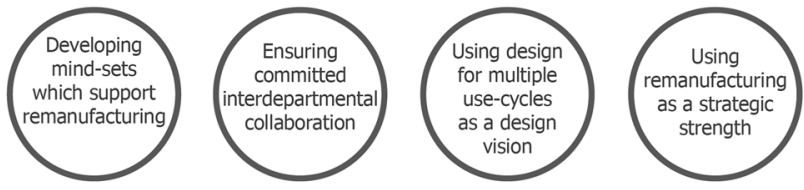

Fig. 4 Strategy Map: An overview of strategic elements, and their interlinkages, of design management for remanufacturing

market [39]. The strategy map presented in this paper describes the ways to develop such advantages through connected actions.

The process perspective of the strategy map connects to the customer perspective as follows. New product requirements find their origins in customer research. The 
strongest argument to adopt a new feature is that it meets market demand. If the case company does not investigate the market needs for remanufactured products, evidence that supports the development of remanufacturable products will be lacking. In their paper, Chouinard et al. [40] stress the importance of researching customer needs in circular product design as well. Bressanelli et al. [41] similarly found a lack of considering user needs for circular design in WEEE-industry research. This paper shows why and how this affects the integration of Design for Remanufacturing. Secondly, directly linked to customer research, is the product identity with which the company presents remanufactured products, i.e. how it promotes quality and relevance, but also how it wins customers' trust. Without this identity, customers, as well as employees, build their own perceptions around remanufactured products (possibly based on inaccurate information or information that is not specific to the case company).

The customer perspective connects to the value perspective, in which the central opportunity for improved implementation is to move towards an integrated business strategy, that includes both newly manufactured and remanufactured products. Earlystage integration allows the case company to anticipate on the earlier mentioned strategic values of remanufacturing. In this way, remanufacturing design guidelines can be included in the design brief, and because of that, receive a design budget. Previously, no budget was allocated to Design for Remanufacturing and it was listed as a recommended activity. This resulted in remanufacturing design requirements being neglected, caused by normal product development time pressure and the traditional focus of engineers. This tendency has been brought up in previous research [7, 5]. This paper explains the underlying causes related to the design brief and design budgets. There is another layer of depth to the business aspects within the value perspective that drives design; the case company focuses on business cases for product designs that will pay back within several years after market introduction. This period only covers a part of one full use-cycle and will therefore be optimised to only serve customer needs in this initial cycle. This means that remanufacturing is already factored out by aiming for a short pay-back period. Stretching this pay-back period would only make a difference when remanufacturing business cases are drafted early on in the process as well, i.e. in the early stages of new product development.

The value perspective links back to the customer perspective through product portfolio management in the early design stage, in which both newly manufactured and remanufactured products should be included. Abbey et al. [42] propose differentiation strategies based on price and brand image to support such a combined portfolio. This paper revealed a need for collaboration with the marketing and sales department, to let strategic designers determine the most optimal way of serving customers, by making use of both product types. The customer perspective requires information originating from the process perspective to accurately build the product portfolio. This information concerns the remanufacturing potential of products and parts. Besides knowing what high-value parts a product contains [28], this study found additional important categories, like software-related and safety-critical parts. Identifying critical parts, again at an early design stage, helps to identify the remanufacturing potential.

Key in offering remanufactured products is to have a predictable inflow of products returning from the market. This is the final link in the strategy map between the process and value perspective. The flow of products returning from the market can be regulated by making early stage agreements with the sales organisation about the product types and targets needed, based on the estimated remanufacturing potential of products. 
A fundamental part of the advice in the strategy map is captured by the learning perspective. Making use of the strategic strengths remanufacturing requires supportive mindsets, design visions, and committed personnel. Instilling this from an early stage will activate employees and give them awareness of the topic, and a sense of ownership and commitment.

The practical value of this research may extend beyond this one case study, because of the rich and deep understanding it provides of the complexity of making remanufacturing part of the company strategyi. The scientific value of this study is the contribution to the body of literature on Design for Remanufacturing - this is one of the first extensive case studies that takes a non-operational perspective and that elucidates the importance of combining a managerial and a design perspective through design management.

Recommendations for further research would therefore be to focus on strategic design elements through (longitudinal) case studies and action research, focused on implementing the proposed solutions in practice, and monitoring their effects. In more detail, this could mean setting up experiments about how to manage product portfolios that include both newly manufactured and remanufactured products. This could also mean building sector-specific insights of customer segments and their needs for remanufactured products. A third option would be to analyse products for their (strategic) potential to be remanufactured in the future in terms of their expectancy to meet customer needs in consecutive usecycles. And a last recommendation would be to further investigate the effect remanufacturing business cases can have for a company, including its strategic value, and how to make them accurate. This would also mean investigating ways to adopt Design for Remanufacturing as a central part of future circular business models.

\section{Conclusions}

The study of this paper is an exploration as to how design management can support the strategic integration of Design for Remanufacturing in industry, and it demonstrates opportunities for further development in other company cases. Unique to this case study is the view on remanufacturing through four different perspectives by means of the balanced scorecard for design management. Combining these multi-angle findings led to a companyspecific strategy map that shows the departmental interrelations and dependencies, and thereby exposes the opportunities for creating new value. Bringing together the four perspectives is crucial for successful product development [34].

In academic literature, product remanufacturing is often viewed as a goal in itself. To obtain increased levels of sustainable production, it could also function as an integrated approach for companies to address not only climate goals and resource efficiency, but let it be part of a wider circular system. To this end, remanufacturing should become more mainstream as it currently is. The extent to which product design can support this, is determined in the early design stage. This case study helped in shedding light on the many soft barriers that are still there.

At the case company, remanufacturing was found to be separate from, and secondary to, the development and production of newly manufactured products. Because of this implicit status, there is a gap when it comes to a design vision and an integrated business strategy for remanufacturing. Closing this gap can be done by using design management to draw up a design strategy that is attuned to developing products for multiple use-cycles. Not addressing this gap will produce suboptimal results and the risk of leaving remanufacturing 
to be a value-retention strategy in isolation. In its current form, the case company utilizes only a part of the possible value that design for remanufacturing can bring. Selecting business models that support optimal product return rates from the market, like offering product-as-a-service, could support the case company to develop such circular design strategies.

Having a design vision and an integrated business strategy that considers both manufacturing and remanufacturing simultaneously, would open up the possibility to find alignment with new product design, take advantage of the strategic value of remanufacturing, and improve upon across-company buy-in for remanufacturing. Deploying the approach of a learning organisation towards such circular economy activities can be adopted through developing supportive mind-sets. These findings may be valid for other companies that have remanufacturing operations, which are separate, as well. This, however, would need to be corroborated through further research.

\section{Appendix}

Interview protocol

Case study: Producer Professional Imaging Equipment

1. General questions

- What is your role within the company? What are your responsibilities? What do you deliver?

- Are you familiar with the different levels of product recovery at your company? Is it clear what these levels mean?

- In your view, what is the general mind-set towards remanufacturing within your department?

- How often is the topic of remanufacturing brought up in your team meetings? For what purpose?

- Do you have targets for remanufacturing?

- What could improve the implementation of Design for Remanufacturing?

2. Questions specific to the remanufacturing department

- Can you describe the remanufacturing process?

- What barriers and opportunities do you see that influence this process?

- Who is responsible for creating business value for remanufacturing?

- How are remanufactured products branded?

- How do you assess the quality remanufactured products?

- Is there a difference in service costs for remanufactured products? If so, what factors are of influence here?

- What market needs does a remanufactured product need to meet?

- What is needed to get customers interested in remanufactured products?

- How do you manage core acquisition?

3. Questions specific to the compliance department

- Who initiated the development of the company standard for ease-of-disassembly? 
- Can you describe the process of developing the company standard for ease-of-disassembly?

- In what way was the company standard introduced and implemented?

- What is the mind-set of the product development department towards this standard?

- What are legislative barriers and enablers to remanufacturing?

- What opportunities do you see for improved implementation of Design for Remanufacturing?

4. Questions specific to the business development and marketing

- Who is responsible for creating business value for remanufacturing?

- What is the process of developing business cases for remanufacturing?

- What is the role of remanufactured products within the product portfolio?

- What are the differences in meeting customer needs when comparing remanufactured products to newly manufactured product?

- What do customers value most about remanufactured products? What is the unique selling point?

- How can you get customers interested in buying remanufactured products?

- What target segments buy remanufactured products?

- To what extent are end-users willing to accept remanufactured products?

- What are reasons to sell remanufactured products?

- What are reasons not to sell remanufactured products?

- What can be learned from past success stories of remanufacturing?

5. Questions specific to the product development department

- What product functions do you design for?

- To what extent does your department have knowledge to design a product for remanufacturing from a technical viewpoint?

- To what extent does your department have knowledge to design a product for remanufacturing from a strategic viewpoint?

- For product X, what are the parts that could serve multiple use-cycles? What parts cannot be reused?

- Do you have product examples of ten years ago for which it is possible to retrofit current-day technologies?

- What market needs does a remanufactured product need to meet?

- How can you get customers interested in buying remanufactured products?

- What is the role of the business development department in designing remanufacturable products.

Funding This paper was funded through EU-funded H2020 project 'Resource-Efficient Circular Product Service Systems' (ReCiPSS), under grant agreement number 776577-2. The study was conducted in consultation with EU funded EIT KIC Raw Materials projects, called: 'Remanufacturing Pathways' (RemanPath), under grant agreement number 17087, and Catalyse Remanufacturing through Design Bootcamp (CARED), under grant agreement number 18024.

Data availability The data is not publicly accessible due to sensitivity reasons. 
Code availability Not applicable.

\section{Declarations}

Conflicts of interest/Competing interests Not applicable.

Ethics approval The ethics approval was covered by signing an NDA with the case study company.

Consent to participate The purpose for data collection was explained to all participants before every interview or observation. The participants were asked for approval to be included in the study separately.

Consent for publication The case study company reviewed the final version of the manuscript and approved it before submission.

Open Access This article is licensed under a Creative Commons Attribution 4.0 International License, which permits use, sharing, adaptation, distribution and reproduction in any medium or format, as long as you give appropriate credit to the original author(s) and the source, provide a link to the Creative Commons licence, and indicate if changes were made. The images or other third party material in this article are included in the article's Creative Commons licence, unless indicated otherwise in a credit line to the material. If material is not included in the article's Creative Commons licence and your intended use is not permitted by statutory regulation or exceeds the permitted use, you will need to obtain permission directly from the copyright holder. To view a copy of this licence, visit http://creativecommons.org/licenses/by/4.0/.

\section{References}

1. International Resource Panel (IRP) (2018) Re-defining value-the manufacturing revolution. Remanufacturing, refurbishment, repair and direct reuse in the circular economy.

2. Hamzaoui-Essoussi L, Linton JD (2014) Offering branded remanufactured/recycled products: at what price? J Remanuf 4(1):9. https://doi.org/10.1186/s13243-014-0009-9

3. Singhal D, Tripathy S, Jena SK (2020) Remanufacturing for the circular economy: Study and evaluation of critical factors. Resour Conserv Recycl 156:104681. https://doi.org/10.1016/j.resconrec.2020. 104681

4. Bakker C, den Hollander M, Van Hinte E, Zijlstra Y (2014) Products that last: product design for circular business models. TU Delft Library, Delft

5. Hatcher GD, Ijomah WL, Windmill JFC (2013) Integrating design for remanufacture into the design process: the operational factors. J Clean Prod 39:200-208. https://doi.org/10.1016/j.jclepro.2012.08. 015

6. Pigosso DC, Zanette ET, Guelere Filho A, Ometto AR, Rozenfeld H (2010) Ecodesign methods focused on remanufacturing. J Clean Prod 18(1):21-31. https://doi.org/10.1016/j.jclepro.2009.09.005

7. Abbey JD, Guide VDR Jr (2018) A typology of remanufacturing in closed-loop supply chains. Int J Prod Res 56(1-2):374-384. https://doi.org/10.1080/00207543.2017.1384078

8. Gray C, Charter M (2008) Remanufacturing and product design. Int J Prod Dev 6(3-4):375-392

9. Ijomah WL, McMahon CA, Hammond GP, Newman ST (2007) Development of robust design-forremanufacturing guidelines to further the aims of sustainable development. Int J Prod Res 45(1819):4513-4536. https://doi.org/10.1080/00207540701450138

10. Zwolinski P, Lopez-Ontiveros MA, Brissaud D (2006) Integrated design of remanufacturable products based on product profiles. J Clean Prod 14(15-16):1333-1345. https://doi.org/10.1016/j.jclepro.2005. 11.028

11. Boorsma N, Balkenende R, Bakker C, Tsui T, Peck D (2020) Incorporating design for remanufacturing in the early design stage: a design management perspective. J Remanuf 1-24. https://doi.org/10.1007/ s13243-020-00090-y

12. Copani G, Behnam S (2018) Remanufacturing with upgrade PSS for new sustainable business models. CIRP J Manufact Sci Technol. https://doi.org/10.1016/j.cirpj.2018.10.005

13. Goodall P, Rosamond E, Harding J (2014) A review of the state of the art in tools and techniques used to evaluate remanufacturing feasibility. J Clean Prod 81:1-15. https://doi.org/10.1016/j.jclepro.2014. 06.014 
14. Schäfer M, Löwer M (2021) Ecodesign-A review of reviews. Sustainability 13(1):315. https://doi. org/10.3390/su13010315

15. Sihvonen S, Partanen J (2016) Implementing environmental considerations within product development practices: a survey on employees' perspectives. J Clean Prod 125:189-203. https://doi.org/10. 1016/j.jclepro.2016.03.023

16. Prendeville S, Bocken N (2017) Design for remanufacturing and circular business models. Sustainability through innovation in product life cycle design. Springer, Singapore, pp 269-283. https:// doi.org/10.1007/978-981-10-0471-1_18

17. Sundin E, Bras B (2005) Making functional sales environmentally and economically beneficial through product remanufacturing. J Clean Prod 13(9):913-925

18. Matsumoto M, Yang S, Martinsen K, Kainuma Y (2016) Trends and research challenges in remanufacturing. Int J Precis Eng Manuf Green Technol 3(1):129-142. https://doi.org/10.1007/ s40684-016-0016-4

19. Sitcharangsie S, Ijomah W, Wong TC (2019) Decision makings in key remanufacturing activities to optimise remanufacturing outcomes: a review. J Clean Prod 232:1465-1481. https://doi.org/10. 1016/j.jclepro.2019.05.204

20. Kurilova-Palisaitiene J, Sundin E, Poksinska B (2018) Remanufacturing challenges and possible lean improvements. J Clean Prod 172:3225-3236. https://doi.org/10.1016/j.jclepro.2017.11.023

21. Li S, Zhang H, Yan W, Jiang Z (2020) A hybrid method of blockchain and case-based reasoning for remanufacturing process planning. J Intell Manuf 1-11. https://doi.org/10.1007/ s10845-020-01618-6

22. Lindkvist Haziri L, Sundin E (2019) Supporting Design for Remanufacturing-a framework for implementing information feedback from remanufacturing to product design. J Remanuf 10:1-20. https://doi.org/10.1007/s13243-019-00077-4

23. Jiang Z, Wang H, Zhang H, Mendis G, Sutherland JW (2019) Value recovery options portfolio optimization for remanufacturing end of life product. J Clean Prod 210:419-431. https://doi.org/10. 1016/j.jclepro.2018.10.316

24. Hatcher GD, Ijomah WL, Windmill JFC (2011) Design for remanufacture: a literature review and future research needs. J Clean Prod 19(18):17. https://doi.org/10.1016/j.jclepro.2011.06.019

25. Karvonen I, Jansson K, Behm K, Vatanen S, Parker D (2017) Identifying recommendations to promote remanufacturing in Europe. J Remanuf 7(2-3):159-179. https://doi.org/10.1007/s13243-017-0038-2

26. Gehin A, Zwolinski P, Brissaud D (2008) A tool to implement sustainable end-of-life strategies in the product development phase. J Clean Prod 16(5):566-576. https://doi.org/10.1016/j.jclepro. 2007.02.012

27. Subramoniam R, Huisingh D, Chinnam RB (2010) Aftermarket remanufacturing strategic planning decision-making framework: theory \& practice. J Clean Prod 18(16-17):1575-1586. https://doi. org/10.1016/j.jclepro.2010.07.022

28. Krikke H, Blanc IL, van de Velde S (2004) Product modularity and the design of closed-loop supply chains. Calif Manag Rev 46(2):23-39

29. D'Adamo I, Rosa P (2016) Remanufacturing in industry: advices from the field. Int J Adv Manuf Technol 86(9-12):2575-2584. https://doi.org/10.1007/s00170-016-8346-5

30. Erichsen PG, Christensen PR (2013) The evolution of the design management field: A journal perspective. Creativity Innov Manag 22(2):107-120. https://doi.org/10.1111/caim.12025

31. Cooper R, Junginger S, Lockwood T (eds) (2013) The handbook of design management. A\&C Black, London

32. Johansson U, Woodilla J (2008) Towards a better paradigmatic partnership between design and management. In International DMI Education Conference.

33. de Borja B (2006) The four powers of design: A value model in design management. Des Manag Rev 17(2):44-53

34. Kaplan RS, Norton DP (2004) Focusing your organization on strategy-with the balanced scorecard. Harvard Business School Publishing, Cambridge

35. Yin RK (2018) Case study research and applications: design and methods. Sage Publications, Thousand Oaks

36. Castleberry A, Nolen A (2018) Thematic analysis of qualitative research data: Is it as easy as it sounds? Curr Pharm Teach Learn 10(6):807-815. https://doi.org/10.1016/j.cpt1.2018.03.019

37. Ansari ZN, Kant R, Shankar R (2019) Prioritizing the performance outcomes due to adoption of critical success factors of supply chain remanufacturing. J Clean Prod 212:779-799. https://doi.org/ 10.1016/j.jclepro.2018.12.038

38. Kerr W, Ryan C (2001) Eco-efficiency gains from remanufacturing: A case study of photocopier remanufacturing at Fuji Xerox Australia. J Clean Prod 9(1):75-81 
39. Östlin J (2008) On remanufacturing systems: analysing and managing material flows and remanufacturing processes. Doctoral dissertation, Institutionen för ekonomisk och industriell utveckling.

40. Chouinard U, Pigosso DC, McAloone TC, Baron L, Achiche S (2019) Potential of circular economy implementation in the mechatronics industry: An exploratory research. J Clean Prod 239:118014. https://doi.org/10.1016/j.jclepro.2019.118014

41. Bressanelli G, Saccani N, Pigosso DC, Perona M (2020) Circular economy in the WEEE industry: a systematic literature review and a research agenda. Sustain Prod Consum. https://doi.org/10.1016/j.spc. 2020.05.007

42. Abbey JD, Meloy MG, Blackburn J, Guide VDR Jr (2015) Consumer markets for remanufactured and refurbished products. Calif Manag Rev 57(4):26-42. https://doi.org/10.1525/cmr.2015.57.4.26

Publisher's Note Springer Nature remains neutral with regard to jurisdictional claims in published maps and institutional affiliations.

\section{Authors and Affiliations}

\section{Nina Boorsma ${ }^{1}$ (D) David Peck ${ }^{2}$ D $\cdot$ Tanya Bakker $^{3} \cdot$ Conny Bakker $^{1}$ (D) Ruud Balkenende ${ }^{1}$}

David Peck

D.P.Peck@tudelft.nl

Tanya Bakker

tanya@3penguins.nl

Conny Bakker

C.A.Bakker@tudelft.nl

Ruud Balkenende

A.R.Balkenende@tudelft.nl

1 Faculty of Industrial Design Engineering, Delft University of Technology, Landbergstraat 15, 2628 CE Delft, The Netherlands

2 Faculty of Architecture and the Built Environment, Delft University of Technology, Julianalaan 134, 2628 BL Delft, The Netherlands

3 3Penguins, Sint Petrus Canisiuslaan 108, 5643 WH Eindhoven, The Netherlands 